\title{
SYMPOSIA OF THE INTERNATIONAL ASTRONOMICAL UNION
}

1. Co-ordination of Galactic Research EDITED BY A. BLAAUW

3. Non-Stable Stars

EDITED BY G. H. HERBIG

4. Radio Astronomy

EDITED BY H. C. VAN DE HULST 


\title{
TRANSACTIONS OF THE \\ INTERNATIONAL ASTRONOMICAL UNION \\ VOLUME IX
}

\author{
EDITED BY \\ P. TH. OOSTERHOFF
}

The ninth volume of Transactions of the International Astronomical Union contains reports on the ninth General Assembly of the Union in Dublin, in Aug.-Sept. 1955. Part I records the ceremonial opening and the two sessions of the General Assembly; the report of the Executive Committee over the years $195^{2-4}$ is reproduced. The resolutions adopted by the assembly are listed in Part II, and Part III contains the draft reports and the reports of the meetings of thirty-nine standing commissions. This part of the volume gives a survey of all astronomical activities during 1952-4. During the assembly joint discussions were held on solar flares, fundamental stars, photoelectric image tubes and their astronomical applications, and turbulence in stellar atmospheres: reports on these scientific meetings will be found in Part IV. Part V lists the standing commissions and members of the Union.

\section{CAMBRIDGE UNIVERSITY PRESS}

Bentley House, 200 Euston Road, London, N.W. I American Branch: 32 East 57 th Street, New York 22, N.Y. 